\title{
Social Anxiety Disorder: Common, Disabling, and Treatable
}

\author{
Mark A. Zamorski, MD, MHSA, and Randy K. Ward, MD
}

Background: Social anxiety disorder (also known as social phobia) is characterized by extreme fear, avoidance, or both of one or more social or performance situations, such as making a presentation, meeting new people, or eating in front of others. This condition is common, with a lifetime prevalence of up to $13 \%$, and one third of affected persons have major dysfunction.

Methods: The English-language literature on social anxiety disorder indexed on MEDLINE was searched using the phrases "social phobia" or "social anxiety disorder;" this search was supplemented with other data sources, such as recent textbooks, to determine common clinical symptoms, differential diagnosis, and management in the primary care setting.

Results: Recognition and treatment of social anxiety disorder is poor; only a small minority of patients with this condition have it appropriately diagnosed or treated. Primary care physicians should suspect social anxiety disorder in patients who have specific symptoms and signs (such as hyperhidrosis, flushing, tremor, and white-coat hypertension), in patients who have symptoms of anxiety (such as chest pain, palpitations, or dizziness), or in patients who have another known anxiety disorder, depression, or substance abuse. Drug treatment consists of serotonin-reuptake inhibitors, monoamine oxidase inhibitors, or high-potency benzodiazepines. A specific type of psychotherapy called cognitive behavioral therapy is another effective treatment, but it is not acceptable or accessible to most patients.

Conclusions: Because social anxiety disorder is common, disabling, and treatable, primary care physicians should intensify their efforts to recognize it.(J Am Board Fam Pract 2000;13:251-60.)

It is normal to be a little nervous when meeting new people, making a presentation, or confronting someone in a position of authority. Such anxiety reflects the simple fact that all social encounters, especially those with unfamiliar or socially advantaged people, entail some risk. We are, after all, social beings, and others in society determine to a certain extent what social benefits we might and might not enjoy.

In social anxiety disorder (also known as social phobia), this normal social anxiety assumes phobic proportions, and sufferers might avoid even innocuous social situations or endure them with extreme distress. Such fear and avoidance are more than an annoyance or a simple personality quirk. Patients with social anxiety disorder suffer disproportionately from depression, other anxiety disorders, substance abuse, and even suicide. ${ }^{1}$ They are more likely to be dis-

Submitted, revised, 5 April 2000.

From the Department of Family Medicine, University of Michigan Medical School, Ann Arbor. Address reprint requests to Mark A. Zamorski, MD, MHSA, Department of Family Medicine, University of Michigan Medical School 4260 Plymouth Rd, Ann Arbor, MI 48109-2702. abled, unemployed, underemployed, and divorced, and on the average they even make less money than persons who do not suffer from the disorder. ${ }^{2}$

Surprisingly, social anxiety disorder is also one of the most common mental illnesses, affecting between $2 \%$ and $13 \%$ of the general population at some point in their lives. ${ }^{3}$ Despite its chronic nature and considerable functional impact, only a few patients with the condition are recognized as having it ${ }^{2,4}$ And despite the growing availability of effective therapies, only a few receive specific treatment. 5,6

The most important role for the primary care physician with respect to social anxiety disorder is to recognize the condition in his or her patients. Once the disorder is recognized, patients can be either referred to a mental health specialist who has experience with the condition or treated medically by the primary care provider.

\section{Methods}

Using MEDLINE, we searched the English language literature on social anxiety disorder using the phrases "social phobia" or "social anxiety disorder." 
We then supplemented the search with other data sources, such as recent textbooks, to determine common clinical symptoms, differential diagnosis, and management in the primary care setting.

\section{Illustrative Cases \\ Generalized Subtype}

A 32-year-old man came in for a physical examination. His only complaint was long-standing, occasional, mild depressive symptoms, and that he felt "down" about $10 \%$ of the time. He related a 10 - to 15-year history of psychotherapy with about 10 different therapists for "self-esteem problems," but he always felt that something was missing, and the therapy never seemed to help much. Because he appeared to be unusually nervous during the interview and examination, he was asked about social anxiety. He readily endorsed substantial social phobic symptoms and consequences dating to early adolescence, including fear or avoidance of many social interactions, difficulty participating in school, and underachievement at work.

\section{Nongeneralized Subtype}

A 27-year-old Latin American man complained of difficulty making presentations at work. He was a very successful management consultant who had had no trouble making presentations or with other social encounters until about 9 months before his visit in the primary care setting. He had had a single panic attack while giving a presentation, and since that time, he experienced substantial anxiety and worry making presentations, even to a small, familiar group. He had no further panic attacks, and his problems with social anxiety were limited to making presentations at work. He acknowledged increasing symptoms of depression since the onset of his social phobia, and he began to believe that he would be better off returning to his homeland, where he would feel more secure.

\section{Description}

Patients with social anxiety disorder are unusually fearful of social interactions with others. Specifically they are afraid of doing something humiliating or embarrassing, or they are concerned about others noticing their anxiety symptoms, such as trembling hands, sweating, or blushing. ${ }^{7}$ Commonly feared are performance situations, such as public speaking or even using a public restroom. Eating, drinking, and writing in front of others, as
Table 1. DSM-IV Criteria for Social Phobia (Social Anxiety Disorder).

A. Marked or persistent fear of one or more social performance situations in which the person is exposed to unfamiliar people or to possible scrutiny by others. The individual fears that he or she will act in a way (or show anxiety symptoms) that will be humiliating or embarrassing. Note: In children there must be evidence of the capacity for age-appropriate social relationships with familiar people, and anxiety must occur in peer settings, not just with interactions with adults

B. Exposure to the feared situation almost always provokes anxiety, which may take the form of a situationally bound or situationally predisposed panic attack. Note: In children, the anxiety may take the form of crying, tantrums, freezing, or shrinking from social situations with unfamiliar people

C. The person realizes that the fear is excessive or unreasonable. Note: In children, this feature may be absent

D. The feared social or performance situations are avoided or else are endured with intense anxiety or distress

E. The avoidance, anxious anticipation, or distress in the feared social or performance situation(s) interferes with the person's normal routine, occupational (academic) functioning, or social activities or relationships, or there is marked distress about having the phobia

F. If the individual is under 18 years, the duration of the symptoms is at least 6 months

G. The fear or avoidance is not due to the direct physiologic effects of a substance (eg, a drug of abuse, a medication) or a general medical condition, and it is not better accounted for by another mental disorder (eg, panic disorder with or without agoraphobia, separation anxiety disorder, body dysmorphic disorder, a pervasive developmental disorder, or schizoid personality disorder)

$H$. If a general medical condition or another mental disorder is present, the fear in criterion $A$ is unrelated to it $(\mathrm{eg}$, trembling in Parkinson disease, abnormal eating behavior in anorexia or bulimia nervosa)

Source: Diagnostic and statistical manual of mental disorders, 4th ed [DSM-IV], pp 416-7, 1994. Copyright 1994, the American Psychiatric Association. Reprinted by permission.

well as interactional situations such as speaking on the telephone, talking to strangers, going to social gatherings, and dealing with authority figures, have been described. ${ }^{8}$ As a result of these fears, patients either avoid social or performance situations or endure them with extreme distress. ${ }^{7}$ Adults with the condition (but not necessarily children) are aware that their fears are excessive. ${ }^{7}$ Although $D i$ agnostic and Statistical Manual of Mental Disorders: $D S M-I V$ criteria sets are often not especially useful to primary care physicians, the set for social anxiety disorder is included as Table 1.

\section{Subtypes}

In the generalized subtype, DSM-IV specifies the presence of serious social anxiety in "most social 

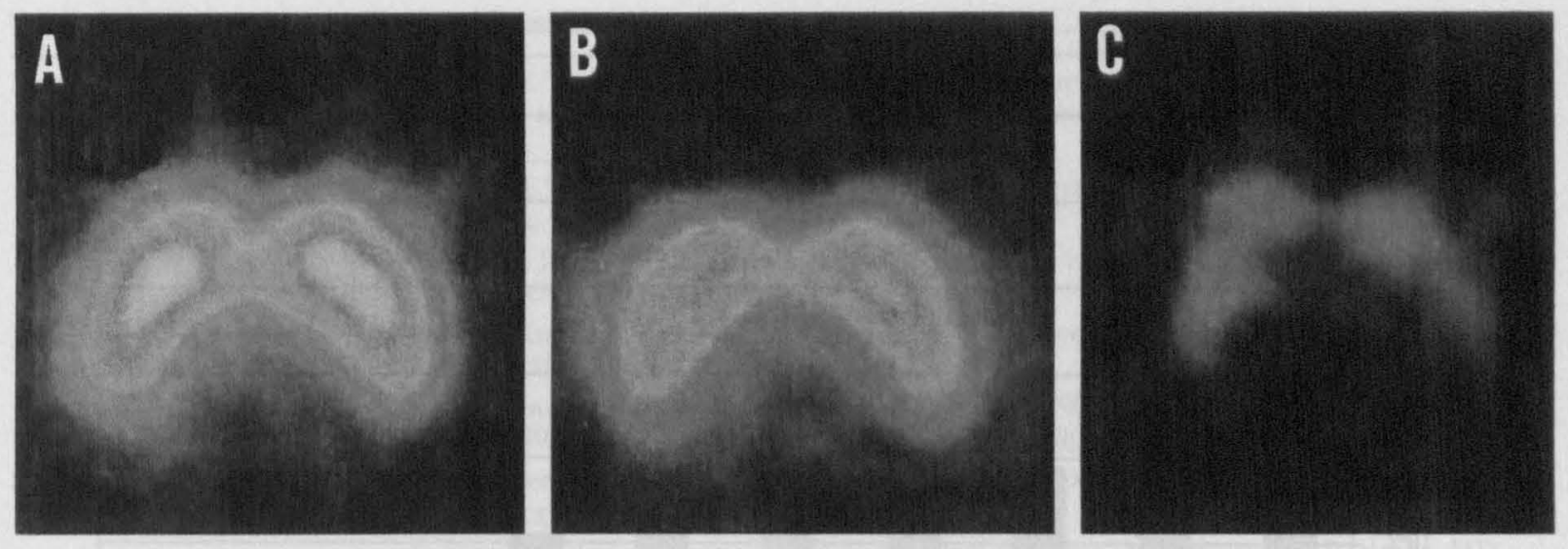

Figure 1. Average striatal dopamine reuptake density measure by positron emission tomography (PET) scan. Differences in dopamine reuptake sites in striatum of (A) 11 controls and (B) 11 patients with social anxiety disorder; (C) subtraction image. Those with social anxiety disorder have substantially lower receptor densities, especially in the right striatum. Source: American Journal of Psychiatry, volume 154, pages 239-42, 1997. Copyright 1997, the American Psychiatric Association. Reprinted by permission.

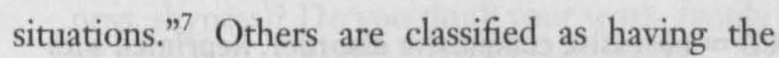
nongeneralized subtype. Avoidant personality disorder, a DSM-IV axis II disorder characterized by a pervasive pattern of social inhibition, feelings of inadequacy, and hypersensitivity to negative evaluation, is also diagnosed in most adults with the generalized type of social anxiety disorder. ${ }^{9}$ These patients appear to have an earlier age of onset and more serious dysfunction. ${ }^{10}$

\section{Clinical Epidemiology}

Once thought to be quite rare, social anxiety disorder is a surprisingly common condition. The National Comorbidity Survey documented a 1-year prevalence of DSM-III-R social anxiety disorder of $7.9 \%$ and a lifetime prevalence of $13.3 \%{ }^{3}$ About one third of these patients was judged to be severely impaired. ${ }^{11}$ The condition is widespread in the primary care setting. ${ }^{6,12}$

The condition has its onset in childhood or young adulthood, with an average age of 22.6 years for the nongeneralized subtype, 16.0 years for the generalized subtype, and 10.9 years for the generalized subtype with comorbid avoidant personality disorder. ${ }^{10}$ Untreated, the condition appears to persist for many years. ${ }^{4}$ In community samples the disorder is more common in women than in men, with a ratio of 1.5 to 1 .

\section{Cause}

The cause of the condition is unknown, but as with other mental disorders, evidence for a biologic con- tribution to the disorder comes from its strong heritability, ${ }^{13,14}$ the effectiveness of a variety of medications in treating the condition, ${ }^{15}$ and even abnormalities in neurotransmitter receptor density shown by positron emission tomography (PET) scans, as shown in Figure $1 .^{16}$

\section{Comorbidity}

As with the other anxiety disorders, comorbidity with other psychiatric disorders is the rule rather than the exception, ${ }^{1}$ especially in more severely affected patients. ${ }^{8}$ Important comorbid disorders are shown in Figure 2.

\section{Signs and Symptoms}

Like many mental disorders, social anxiety disorder goes unrecognized in both clinical and mental health settings. ${ }^{1,6,12}$ In one study of a large managed care population, only 1 of 200 patients with this condition was receiving treatment for it by a physician or therapist. ${ }^{2}$

Typical complaints include hyperhidrosis, tremor, blushing or flushing, dry mouth, stuttering or cracking voice, or "butterflies in the stomach."17 These signs and symptoms might also be apparent, along with hypertension and tachycardia, to the observant clinician, especially during the first visit.

Occasional patients will complain of panic phenomenology ${ }^{7}$ triggered by social or performance situations. 


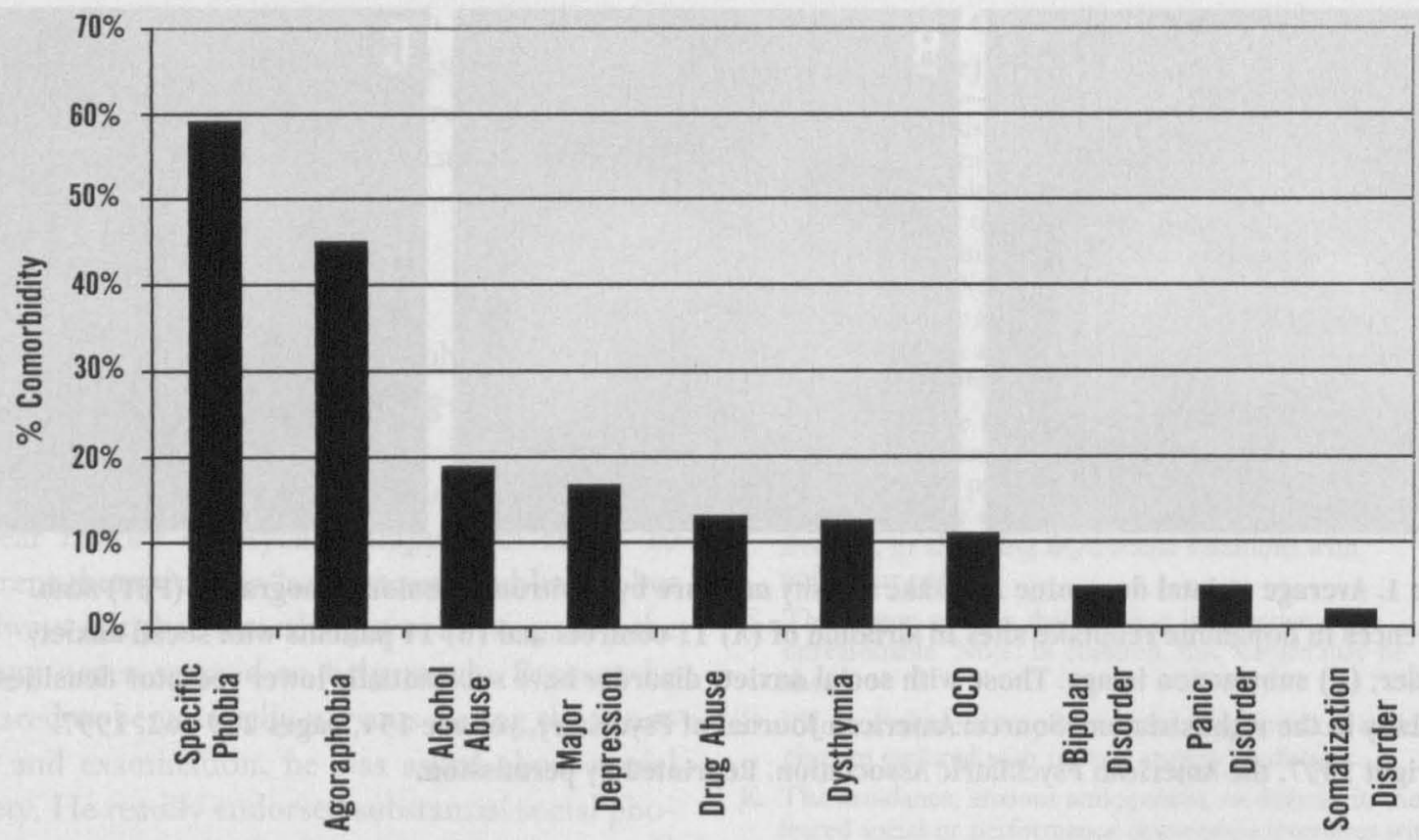

Figure 2. Comorbid conditions of social anxiety disorder. $\mathrm{OCD}=$ obsessive compulsive disorder. Reprinted with permission from Schneier FR, Johnson J, Hornig CD, Liebowitz MR, Weissman MM. Social phobia. Comorbidity and morbidity in an epidemiologic sample. Arch Gen Psychiatry 1992;49:282-8. Copyright 1992, American Medical Association.

\section{Generalized or Anticipatory Anxiety}

Somatic manifestations of anxiety are common in the primary care setting; common ones include chest pain, palpitations, shortness of breath, dizziness, fatigue, insomnia, and gastrointestinal complaints. If a wide variety of social or performance situations are feared, and especially if unpredictable situations are feared, patients with social anxiety disorder can feel restless, anxious, keyed-up, and on edge, constantly fearing a chance social encounter.

\section{Substance Abuse and Other Comorbid Psychiatric Disorders}

Some patients struggling with substance abuse, especially alcohol, will have social anxiety disorder. Exploring an early history of drinking to tolerate social situations will often disclose the association. Patients with conditions diagnosed as depression, panic disorder with or without agoraphobia, obsessive compulsive disorder, and generalized anxiety disorder have comorbid social anxiety disorder often enough to make it worthwhile asking some screening questions for the condition. ${ }^{8}$ One recent study showed that strong positive responses to the three following questions have a sensitivity of $89 \%$ and a specificity of $90 \%$ for social anxiety disorder. ${ }^{2}$
1. Is being embarrassed or looking stupid among your worst fears?

2. Does fear of embarrassment cause you to avoid doing things or speaking to people?

3. Do you avoid activities in which you are the center of attention?

\section{Differential Diagnosis \\ Medical Conditions}

No medical condition causes the characteristic symptom complex of social anxiety disorder. If attention is paid to only a single physical complaint of anxious patients (eg, chest pain, palpitations, sweating), the differential diagnosis will be extensive, but most primary care physicians are familiar with the diagnosis of these complaints.

\section{Normal Social Anxiety}

The distinction between normal social anxiety and social anxiety disorder is not always clear-cut, and the DSM-IV criteria (Table 1$)^{7}$ leave some room for uncertainty. Several key factors are helpful in diagnosis:

1. Does the patient experience serious dysfunction or role impairment? One way of exploring 


\begin{tabular}{ll}
\hline Books & Bourne EJ. The anxiety and phobia workbook: a step-by-step program for curing yourself of \\
extreme anxiety, panic attacks, and phobias. 2nd edition. New York: Fine Communications, \\
1995 \\
Rapee RM. Overcoming shyness and social phobia: a step-by-step guide. Northvale, NJ: Jason \\
Aronson, 1998 \\
Greist JH; Jefferson JW; Katzelnick DJ. Social phobia: a guide. Madison, Wis: Madison Institute \\
of Medicine, 1997. \\
Anxiety Disorders Association of America, 11900 Parklawn Drive, Suite 100, Rockville, MD \\
20852. (301) 231-9350. http://www.adaa.org \\
National Institutes of Mental Health, Room 7C-02, MSC 8030, 5600 Fishers Lane, Bethesda, \\
MD 20892. 1-88-88-ANXIETY. http://www.nimh.nih.gov \\
for office use \\
Toastmasters International, PO Box 9052, Mission Viejo, CA 92690. (949) 858-8255. \\
http://www.toastmasters.org \\
Anxiety Disorders Association of America, 11900 Parklawn Drive, Suite 100, Rockville, MD \\
20852. (301) 231-9350. http://www.adaa.org
\end{tabular}

this question is to ask patients: "What sorts of things do you think you've missed out on as a result of your social anxiety (self-consciousness, shyness)? Do you think your work, family life, or personal life have been affected?"

2. Does the patient avoid social situations? To assess avoidance, ask: "Have you found yourself avoiding situations because of your anxiety (worry, shyness, self-consciousness)?"

3. Does the patient specifically fear doing something humiliating or embarrassing, or fear that others will notice the sufferer's anxiety? Ask: "What are your specific fears about (a particular feared situation)? Are you concerned that you might do something embarrassing or humiliating? Are you concerned that others will notice your sweating hands, trembling, etc?

4. Has the patient resorted to unusual or destructive means to control their anxiety? Specifically ask about using drugs or alcohol to feel comfortable in social situations.

5. Are the patient's feared social performance situations unusual? Odd fears such as writing, eating, or drinking in public are not common in healthy individuals.

A variety of mental disorders, including panic disorder, agoraphobia, depressive disorders, obsessive-compulsive disorder, generalized anxiety disorder, psychotic disorders, and body dysmorphic disorder, need to be distinguished from social anxiety disorder; DSM-IV ${ }^{7}$ highlights some useful distinguishing features. Because some of these disorders are commonly comorbid with social anxiety disorder, several can be diagnosed in a given patient.

\section{Treatment Options}

Social anxiety disorder responds to a variety of different treatments. Nevertheless, it is important to set reasonable patient expectations. Patients with social anxiety disorder get better more slowly and often less completely than those with more familiar psychiatric disorders, such as depression or panic disorder.

\section{Patient Education}

Patients with social anxiety disorder often feel a great sense of relief when they learn that their secret problem has a name, a biologic contribution, and effective trearments. Occasional patients can successfully guide themselves through a cognitive behavioral therapy program using a workbook (Table 2).

\section{Support Groups}

Support groups have not been specifically evaluated for the treatment of social phobia, but some patients find them helpful. The international selfhelp program called Toastmasters (Table 2) is very helpful for people with public-speaking phobia. ${ }^{18}$

\section{Cognitive Bebavioral Therapy}

Cognitive theory suggests that patients with social anxiety disorder possess learned, irrational fears of negative evaluation that pervade their experience of social situations. These fears lead to their symptoms of anxiety. Cognitive therapy trains patients to recognize, analyze, and dispute these irrational fears. Behavioral therapy involves exposing patients to graded exposures and simulations of anxietyprovoking situations, which leads to desensitization 
and severing the link between the social situations and anxiety. ${ }^{19,20}$

Cognitive behavioral therapy combines these therapies in a specialized form of psychotherapy, with specific goals and structure and a time-limited course. Cognitive behavioral therapy for social anxiety disorder is usually done in a group setting, allowing patients to try out their new social behaviors in a safer environment. There are data to support the efficacy of cognitive behavioral therapy as a primary treatment of social anxiety disorder. Cognitive behavioral therapy appears to be as effective as pharmacotherapy and is associated with a relatively durable response. In clinical practice cognitive behavioral therapy can be used as a primary treatment or in conjunction with pharmacotherapy. ${ }^{21,22}$

\section{Pharmacotherapy}

Selective serotonin reuptake inhibitors (SSRIs) have become the most widely recommended medications for social anxiety disorder. ${ }^{15,18}$ Most SSRIs have been studied at least in an uncontrolled fashion, and all appear to be effective. ${ }^{23}$ Paroxetine (Paxil) has become the best-studied agent in this class, and it is the only one to have received FDA approval for this indication at the present time. As with obsessive-compulsive behavior, higher doses (eg, an average of $37 \mathrm{mg} / \mathrm{d}$ of paroxetine) are required, and the rate of improvement is slow. As shown in Figure 3, symptom control and improvement in functioning occurs within at least 12 weeks. Social anxiety disorder is an intrinsically refractory disorder, and only about one half of patients taking SSRIs will realize a substantial improvement in their symptoms. Given that high doses for extended periods are required for the condition, medication side effects are a major obstacle to treatment.

Benzodiazepines, especially the newer, high-potency agents such as alprazolam (Xanax), clonazepam (Klonopin), and lorazepam (Ativan), have also been shown to be effective in both the generalized and nongeneralized forms of social anxiety disorder. ${ }^{24}$ Of these medications, clonazepam offers the advantage of requiring only twice-a-day dosing, ${ }^{25}$ and it might be less likely to be misused. ${ }^{26}$ Average doses in clinical trials have been about 2.5 $\mathrm{mg} / \mathrm{d}$ of clonazepam or its equivalent. ${ }^{27}$

Monoamine oxidase inhibitors (MAOIs) were the first agents to be shown to have important activity in social anxiety disorder. ${ }^{24}$ Because of their side-effect profile and their potentially fatal drugdrug and drug-food interactions, they are seldom

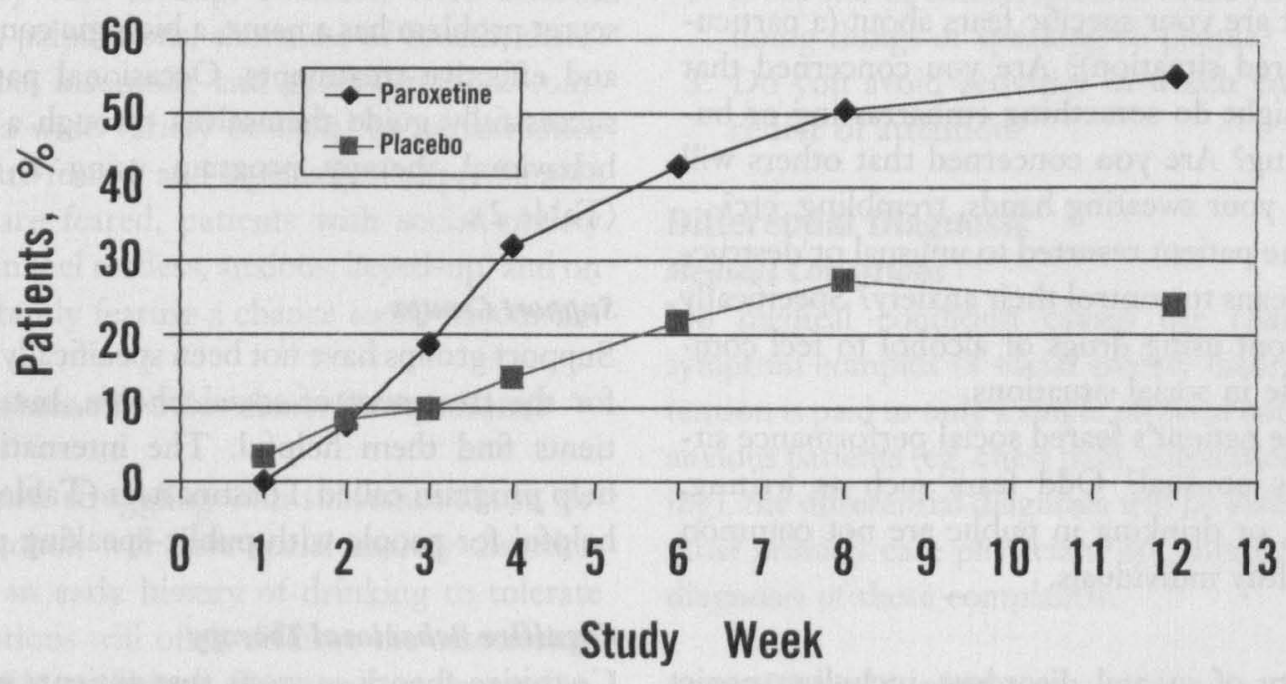

Figure 3. Efficacy of paroxetine in social anxiety disorder. Percentage of patients taking paroxetine or placebo (from a randomized, double-blind study) considered therapeutic responders, using Clinical Global Impression Global Improvement Item (standardized method of assessing improvement in mental disorders) (paroxetine vs placebo, $P=.001$ ). Note that up to 12 weeks of therapy were required for optimal effect. Mean paroxetine dosage in this study was $36.6 \mathrm{mg} / \mathrm{d}$ (SD $12.1 \mathrm{mg}$ ). Reproduced with permission from: Stein MB, Liebowitz MR, Lydiard RB, Pitts CD, Bushnell W, Gergel I. Paroxetine treatment of generalized social phobia (social anxiety disorder): a randomized controlled trial. JAMA 1998;280:708-13. Copyrighted 1998, American Medical Association. 
Table 3. Treatment Implications of Common Comorbid Conditions Associated With Social Anxiety Disorder.

$\begin{aligned} & \text { Comorbid } \\ & \text { Conditions }\end{aligned}$
$\begin{aligned} & \text { Depression, dysthymia } \\ & \text { Bipolar disorder }\end{aligned}$
$\begin{aligned} & \text { SSRI (or for refractory cases, MAOI) is preferred. Avoid benzodiazepines } \\ & \text { Avoid antidepressants unless administered with mood stabilizer, such as lithium or } \\ & \text { valproate (Depakote) } \\ & \text { SSRI (or MAOI for refractory cases) preferred; benzodiazepines will also treat both } \\ & \text { disorders, as will cognitive behavioral therapy }\end{aligned}$
$\begin{aligned} & \text { Obsessive-compulsive disorder } \\ & \text { SSRI preferred; higher doses might be required. Specific forms of behavior therapy } \\ & \text { effective in OCD. Given refractory, complex nature of both OCD and social anxiety } \\ & \text { disorder, referral of patients with this pattern of comorbid conditions to anxiety } \\ & \text { disorders specialist is strongly encouraged }\end{aligned}$
$\begin{aligned} & \text { SSRI is preferred; cognitive behavioral therapy will treat both disorders. } \\ & \text { Benzodiazepines (either alone or with an SSRI) will also treat both disorders }\end{aligned}$
Cognitive behavioral therapy preferred; most patients with agoraphobia will also
benefit from an SSRI
Benzodiazepines contraindicated. Patients need independent treatment of substance
abuse in addition to social anxiety disorder
Pabstance abuse
Patients with this pattern of comorbidity tend to be most severely affected, have more
comorbid conditions, and tend to have incomplete responses to SSRI therapy.
Referral to anxiety disorders specialist is strongly encouraged

SSRI = selective serotonin reuptake inhibitor, $\mathrm{MAOI}=$ monoamine oxidase inhibitor.

used, but they are a viable treatment option for patients refractory to treatment. ${ }^{18}$

Tricyclic antidepressants have been shown to be surprisingly ineffective in the treatment of social anxiety disorder. ${ }^{18,23}$ Even though $\beta$-adrenergic blockers have been used to treat social phobia, not much has been published that supports their use except for occasional patients with simple performance anxiety. ${ }^{24}$ Buspirone (BuSpar) has shown similarly disappointing results, ${ }^{28}$ although there is limited experience with using it in conjunction with an SSRI for refractory cases. ${ }^{29}$ Bupropion (Wellbutrin) has not been well studied in social anxiety disorder, ${ }^{30}$ but its performance in other anxiety disorders has been disappointing. ${ }^{31}$

\section{Combination Therapy}

Anxiety specialists often use combinations of medications to treat social anxiety disorder, but there is little more than anecdotal experience with them. ${ }^{18}$ Anxiety disorder clinics commonly care for patients with social anxiety disorder using a combination of both medications and cognitive behavioral therapy.

\section{Selection of Therapy}

For patients with isolated public-speaking phobia, self-help groups (eg, Toastmasters) or cognitive behavioral therapy are usually preferred. ${ }^{15}$ An occasional patient will find $\beta$-adrenergic blockers helpful, but much of the relief is probably attribut- able to a placebo response. ${ }^{24}$ As-needed benzodiazepines are usually not indicated, unless the circumstances are truly extraordinary, and time does not allow other approaches. ${ }^{24}$

For patients who suffer from more extensive fear or avoidance, an SSRI or cognitive behavioral therapy (or both) are reasonable choices, depending on patient preferences and availability of a therapist. ${ }^{15,18}$ Because of its well-established efficacy and known dose- and time-response curve, ${ }^{32}$ paroxetine (Paxil) is a good choice among the SSRIs. Preliminary evidence supports the use of other SSRIs ${ }^{33-37}$ as well, so if one SSRI is not effective (or not tolerated), switching to another SSRI might be effective, just as in depression. For clinicians who are comfortable using them, the higher doses of the high-potency benzodiazepines are an appropriate alternative (either alone or in combination with an SSRI). ${ }^{24}$ Comorbid conditions are important when selecting therapies of social anxiety disorder; treatment implications are shown in Table 3.

\section{Indications for Referral}

If available and accessible, immediate referral to an anxiety specialist or program experienced in treating social phobia with cognitive behavioral therapy and medications ensures confirmation of the diagnosis, assessment of important comorbid conditions, extensive patient education, and more expe- 
rienced selection and implementation of therapies. If such services are not available locally, clinicians should consider referral for patients who fail to benefit from (or fail to tolerate) adequate doses of several SSRIs with or without a high-potency benzodiazepine. Such patients can benefit from a MAOI, cognitive behavioral therapy, or more complex or experimental regimens. Patients with multiple comorbid conditions (Table 3) can also benefit from evaluation by a qualified specialist.

The lack of recognition and appropriate treatment of the disorder in the community, even among the majority of patients who have sought out mental health services, shows that currently most mental health professionals are not capable of diagnosing and treating this condition. Accordingly, referral to a regional center with special expertise in anxiety disorders is strongly encouraged. Such centers can be found in larger urban areas and in association with larger teaching hospitals.

\section{Social Anxiety Disorder During Childhood and Adolescence}

Social anxiety disorder exists in childhood, and the somatic symptoms and types of situations feared are similar to those of the adult form of the disorder. Onset in childhood appears to lead to a more severe and refractory course. A major difficulty in the diagnosis is the child's immature cognitive and verbal abilities, which limit self-report and the usefulness of the subjective symptoms of the disorder. ${ }^{17}$

Social anxiety disorder in children can elude diagnosis because it is not primarily an "acting out" type of disorder. In school, these children can be seen as quiet and well behaved, or "just shy." They might come to attention because of school refusal, social isolation, or oppositional behavior when placed in situations where they are forced to interact with others. ${ }^{17}$ Undiagnosed and untreated social anxiety disorder can lead to the development of other comorbid psychiatric disorders, such as drug abuse or depression. ${ }^{17}$

Referral to a child psychiatrist or psychologist is recommended so that children with clinically severe symptoms can be evaluated appropriately. Although there is a lack of controlled studies on the various treatment methods used to treat this disorder in children, individual and family psychotherapy and pharmacotherapy with antidepressants and benzodiazepines have been used as components of comprehensive treatment plans. ${ }^{38}$

\section{Follow-Up of Patients}

Patients with anxiety disorders are unusually sensitive to medication side effects, especially the agitation or jitteriness that can occur early in the course of treatment with SSRIs. Accordingly, it is usually safest to initiate the medication at one half of the usual starting dose for depression, eg, $10 \mathrm{mg} / \mathrm{d}$ of paroxetine. The dosage is increased every few days to a week until the target dose has been reached (usually near the maximum of the recommended antidepressant dosage). Once the target dosage has been reached, the medication should be continued for at least 12 weeks before concluding the medication trial to be a success or failure. Visits every 1 to 2 weeks are appropriate as the medication dosage is being increased; brief monthly visits are appropriate as the patient is waiting to see benefits and side effects.

Social phobia is a chronic condition, and many patients will require life-long drug therapy to achieve symptom control. Firm guidelines do not exist for when a trial off medication is indicated, but most experts will consider a trial off medication if the patient's symptoms have been well controlled for 6 to 12 months or more. ${ }^{15,18,23}$

\section{Conclusions}

Once aware of the diagnosis and its implications, clinicians will be able to recognize social anxiety disorder among their patients with anxiety, depression, or substance abuse. Effective treatment with an SSRI, cognitive behavioral therapy, or other interventions can help patients with this disorder lead more happy and productive lives.

\section{References}

1. Schneier FR, Johnson J, Hornig CD, Liebowitz MR, Weissman MM. Social phobia. Comorbidity and morbidity in an epidemiologic sample. Arch Gen Psychiatry 1992;49:282-8.

2. Kobak KA, Schaettle SC, Greist JH, Jefferson JW, Katzelnick DJ, Dottl SL. Computer-administered rating scales for social anxiety in a clinical drug trial. Depress Anxiety 1998;7:97-104.

3. Kessler RC, McGonagle KA, Zhao S, et al. Lifetime and 12-month prevalence of DSM-III-R psychiatric disorders in the United States. Results from the National Comorbidity Survey. Arch Gen Psychiatry 1994;51:8-19.

4. Davidson JR, Hughes DL, George LK, Blazer DG. The epidemiology of social phobia: findings from 
the Duke Epidemiological Catchment Area Study. Psychol Med 1993;23:709-18.

5. Pollard CA, Henderson JG, Frank M, et al. Helpseeking patterns of anxiety-disordered individuals in the general population. J Anxiety Disord 1989;3: 131-8.

6. Weiller E, Bisserbe JC, Boyer P, Lepine JP, Lecrubier Y. Social phobia in general health care: an unrecognised undertreated disabling disorder. Br J Psychiatry 1996;168:169-74.

7. American Psychiatric Association. Diagnostic and statistical manual of mental disorders: DSM-IV. Washington, DC: American Psychiatric Press, 1994.

8. Hazen AL, Stein MB. Clinical phenomenology and comorbidity. In: Stein MB, editor. Social phobia: clinical and research perspectives. Washington, DC: American Psychiatric Press, 1995:3-41.

9. Heimberg RG, Holt CS, Schneier FR, et al. The issue of subtypes in the diagnosis of social phobia. J Anxiety Disord 1993;7:249-69.

10. Holt CS, Heimberg RG, Hope DA. Avoidant personality disorder and the generalized subtype of social phobia. J Abnorm Psychol 1992;101:318-25.

11. Walker JR, Stein MB. Epidemiology. In: Stein MB, editor. Social phobia: clinical and research perspectives. Washington, DC: American Psychiatric Press, 1995:43-75.

12. Stein $M B, M c Q u a i d ~ J R$, Laffaye $C, M c$ Cahill $M E$. Social phobia in the primary care medical setting. $J$ Fam Pract 1999;48:514-9.

13. Stein MB, Chartier MJ, Hazen AL, et al. A directinterview family study of generalized social phobia. Am J Psychiatry 1998;155:90-7.

14. Knowles JA, Mannuzza S, Fyer AJ. Heritability of social phobia. In: Stein MB, editor. Social phobia: clinical and research perspectives. Washington, DC: American Psychiatric Press, 1995:147-62.

15. den Boer JA. Social phobia: epidemiology, recognition, and treatment. BMJ 1997;315:796-800.

16. Tiihonen J, Kuikka J, Bergstrom K, Lepola U, Koponen H, Leinonen E. Dopamine reuptake site densities in patients with social phobia. Am J Psychiatry 1997;154:239-42.

17. Beidel DC. Social anxiety disorder: etiology and early clinical presentation. J Clin Psychiatry 1998; 59(Suppl 17):27-32.

18. Ballenger JC, Davidson JR, Lecrubier Y, et al. Consensus statement on social anxiety disorder from the International Consensus Group on Depression and Anxiety. J Clin Psychiatry 1998;59 (Suppl 17):5460.

19. Antony MM. Assessment and treatment of social phobia. Can J Psychiatry 1997;42:826-34.

20. Mattick RP, Page A, Lampe L. Cognitive and behavioral aspects. In: Stein MB, editor. Social phobia: clinical and research perspectives. Washington, DC: American Psychiatric Press, 1995:189-227.
21. Stravynski A, Greenberg D. The treatment of social phobia: a critical assessment.. Acta Psychiatr Scand 1998;98:171-81.

22. Juster HR, Heimberg RG. Social phobia. Longitudinal course and long-term outcome of cognitivebehavioral treatment. Psychiatr Clin North Am 1995;18:821-42.

23. Schneier FR. Monoamine oxidase inhibitors, selective serotonin reuptake inhibitors, and other antidepressants in pharmacotherapy. In: Stein MB, editor. Social phobia: clinical and research perspectives. Washington, DC: American Psychiatric Press, 1995:347-74.

24. Sutherland SM, Davidson JRT. Beta-blockers and benzodiazepines in pharmacotherapy. In: Stein MB, editor. Social phobia: clinical and research perspectives. Washington, DC: American Psychiatric Press, 1995:323-46.

25. Racagni G, Masotto C, Steardo L. Pharmacology of anxiolytic drugs. In: Costa E, Silva J, Prilipko LL, editors. WHO expert series on neuroscience. Seattle: Hogrefe \& Huber, 1998:118.

26. American Psychiatric Association Task Force on Benzodiazepine Dependence Toxicity, and Abuse. Benzodiazepine dependence, toxicity, and abuse. Washington, DC: American Psychiatric Press, 1990.

27. Davidson JR, Ford SM, Smith RD, Potts NL. Longterm treatment of social phobia with clonazepam. J Clin Psychiatry 1991;52(Suppl):16-20.

28. van Vliet IM, den Boer JA, Westenberg HG, Pian $\mathrm{KL}$. Clinical effects of buspirone in social phobia: a double-blind placebo-controlled study. J Clin Psychiatry 1997;58:164-8.

29. Van Ameringen $M$, Mancini C, Wilson C. Buspirone augmentation of selective serotonin reuptake inhibitors (SSRIs) in social phobia. J Affect Disord 1996; 39:115-21.

30. Emmanuel NP, Lydiard RB, Ballenger JC. Treatment of social phobia with bupropion. J Clin Psychopharmacol 1991;11:276-7.

31. Sheehan DV, Davidson J, Manschreck T, Van Wyck Fleet J. Lack of efficacy of a new antidepressant (bupropion) in the treatment of panic disorder with phobias. J Clin Psychopharmacol 1983;3:28-31.

32. Stein $M B$, Liebowitz MR, Lydiard RB, Pitts $C D$, Bushnell W, Gergel I. Paroxetine treatment of generalized social phobia (social anxiety disorder): a randomized controlled trial. JAMA 1998;280:708-13.

33. Katzelnick DJ, Kobak KA, Greist JH, Jefferson JW, Mantle JM, Serlin RC. Sertraline for social phobia: a double-blind, placebo-controlled crossover study. Am J Psychiatry 1995;152:1368-71.

34. Van Ameringen M, Mancini C, Streiner DL. Fluoxetine efficacy in social phobia. J Clin Psychiatry 1993;54:27-32.

35. den Boer JA, Westenberg HG, De Leeuw AS, van Viet IM. Biological dissection of anxiety disorders: the clinical role of selective serotonin reuptake in- 
hibitors with particular reference to fluvoxamine. Int Clin Psychopharmacol 1995;9(Suppl 4):47-52.

36. Bouwer C, Stein DJ. Use of the selective serotonin reuptake inhibitor citalopram in the treatment of generalized social phobia. J Affect Disord 1998;49: $79-82$.
37. Worthington JJ 3rd, Zucker BG, Fones CS, Otto $M W$, Pollack $M H$. Nefazodone for social phobia: a clinical case series. Depress Anxiety 1998;8:131-3.

38. Albano AM, Chorpita BF. Treatment of anxiety disorders of childhood. Psychiatr Clin North Am 1995; 18:767-84. 